\title{
The role of heme oxygenase-I (HO-I) in the regulation of inflammatory reaction, neuronal cell proliferation and apoptosis in rats after intracerebral hemorrhage $(\mathrm{ICH})$
}

\author{
This article was published in the following Dove Press journal: \\ Neuropsychiatric Disease and Treatment \\ 28 December 2016 \\ Number of times this article has been viewed
}

\author{
Xuezheng Fan' \\ Linshen $\mathrm{Mu}^{2}$ \\ 'Department of Neurosurgery, \\ People's Hospital of Guangming \\ New District, Shenzhen, Guangdong, \\ People's Republic of China; \\ ${ }^{2}$ Department of Neurosurgery, \\ Guangzhou Medical University \\ Affiliated Brain Hospital, Guangzhou, \\ Guangdong, People's Republic of \\ China
}

Objective: To investigate the role of heme oxygenase-1 (HO-1) in the regulation of inflammatory reaction, neuronal cell proliferation and apoptosis in rats after intracerebral hemorrhage (ICH). Methods: Thirty-six adult Sprague Dawley (SD) male rats were randomly divided into sham operation, ICH and zinc protoporphyrin (ZPP) group. Rats (except for the sham operation group) were given $50 \mu \mathrm{L}$ stereotactic injection of autologous blood from the femoral artery into the caudate nucleus, to establish an ICH model. In addition, rats in the ZPP group were given $10 \mathrm{mg} / \mathrm{kg}$ intraperitoneal injection of ZPP. At day 3 postoperative, neurobehavioral changes and brain water content were evaluated, brain tissue HO-1 expression was detected with immunohistochemistry and reverse transcription polymerase chain reaction (RT-PCR), brain tissue apoptosis was evaluated with TUNEL method, Caspase 3, Caspase 8 and Caspase 9 activity were detected with colorimetric method, level of TNF- $\alpha$, IL-1 $\beta$, IL- 6 and IL- 8 were measured with the enzyme-linked immunosorbent assay (ELISA),

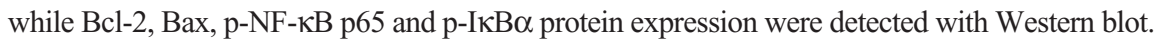

Results: ICH group compared to sham operation: HO-1 positive rate and mRNA expression were increased, neurological deficit score and cell apoptosis rate were increased, Caspase 3, Caspase 8 and Caspase 9 activity were increased, level of TNF- $\alpha$, IL-1 $\beta$, IL- 6 and IL- 8 were increased, Bcl- 2

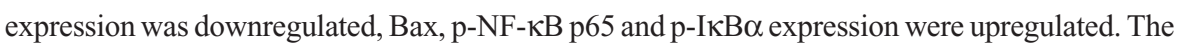
differences were statistically significant $(P<0.01)$. ZPP group compared to ICH: HO-1 positive rate and mRNA expression were decreased, neurological deficit score and cell apoptosis rate were decreased, Caspase 3, Caspase 8, Caspase 9 activity were decreased, level of TNF- $\alpha$, IL-1 $\beta$,

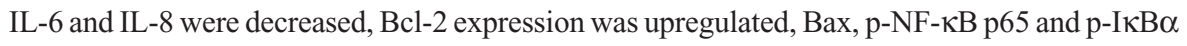
expression were downregulated, and the differences were statistically significant $(P<0.01)$.

Conclusion: HO-1 inhibitor, ZPP does have a protective effect on ICH rats. This might be due to its inhibition to the inflammatory reaction and neuronal cell apoptosis.

Keywords: heme oxygenase-1, intracerebral hemorrhage, inflammatory reaction, apoptosis

\section{Introduction}

Intracerebral hemorrhage $(\mathrm{ICH})$ is one of the important subtypes of stroke. It is a common disease of the nervous system caused by rupture of the cerebral arteries and release of blood into the brain parenchyma. Its disability and mortality rate remains high, and has a serious impact on human health and quality of life. ${ }^{1,2}$ Studies showed that ICH accounts for $15 \%$ of stroke in the West, and 35\% in Asia, and the prognosis is poor. ${ }^{3}$ At present, the main management techniques for $\mathrm{ICH}$ include reducing intracranial pressure, use of neurotrophic substances and surgical evacuation of hematoma. However,
Correspondence: Xuezheng Fan Department of Neurosurgery, People's Hospital of Guangming New District, 4253 Songbai Road, Gongming Street, Guangming New District, Shenzhen 518106, Guangdong, People's Republic of China

Tel +86 I5I 077I 38I2

Email fan_xuezheng@163.com 
the specificity is not high. ${ }^{4}$ The reason might be that compared to the injury caused by hematoma due to mass occupying effect and mechanical compression, the effect of secondary injury due to inflammatory reaction and apoptosis particularly free radical cascade and release of thrombin to the prognosis of ICH is larger..$^{5-7}$

Studies showed that formation of cerebral edema at early stage post $\mathrm{ICH}$ is mainly related to thrombin release, while at late stage (3d) it is mainly related to heme degradation products, and this period is closely related to the recovery of neurological function. ${ }^{8,9}$ Degradation of heme is mainly mediated by heme oxygenase (HO). HO mainly consists of three isoforms, HO-1, HO-2 and HO-3, and among these $\mathrm{HO}-1$ is the main rate-limiting enzyme. Under normal physiological conditions, HO-1 expression in brain is very low or none at all. It increases significantly during ICH process, usually peaks at stage $3 \mathrm{~d}-7 \mathrm{~d}$, post ICH. Use of HO-1 inhibitor in ICH does have significant therapeutic effect. However, reports of specific mechanism of action is scarce, and mainly focused on the oxidative stress reaction process. ${ }^{8-10} \mathrm{HO}-1$ is closely related to oxidative stress reaction, inflammatory reaction and process of cell apoptosis, etc. ${ }^{11,12}$ suggesting that it may also have its influence via its effects on the inflammatory reaction and process of cell apoptosis after $\mathrm{ICH}$.

Thus, in this study, replicate rat model of $\mathrm{ICH}$ was established and intervention of HO-1 inhibitor, zinc protoporphyrin (ZPP) were used to evaluate its effect on the inflammatory reaction, apoptosis changes and its related mechanisms in ICH rats.

\section{Materials and methods Animal model}

Thirty-six clean and healthy, adult Sprague Dawley (SD) male rats, weighing 200 \pm 20 g, purchased from Shanghai SLAC Laboratory Animals Corporation Limited, Shanghai, People's Republic of China (Certificate: SCXK [Shanghai] 2012-0002) were used. Rats were kept at indoor temperature which was controlled at $23^{\circ} \mathrm{C} \pm 2^{\circ} \mathrm{C}$ and were free to take in food and water. All protocols involving animals were approved by the Institutional Review Board of the People's Hospital of Guangming New District. All experiments were performed in accordance with the National Institutes of Health guide for the care and use of Laboratory animals (NIH Publications No. 8023, revised 1978).

\section{Main reagents and instruments}

ZPP $50 \mathrm{mg} /$ vial was obtained from Sigma-Aldrich Co., St Louis, MO, USA. Bicinchoninic acid (BCA) protein assay kit, mouse anti-glyceraldehyde 3-phosphate dehydrogenase (GAPDH) monoclonal antibody and horseradish peroxidase labeled goat anti-rabbit immunoglobulin $\mathrm{G}(\mathrm{IgG})(\mathrm{H}+\mathrm{L})$ were purchased from Beyotime Institute of Biotechnology, Haimen, Jiangsu, People's Republic of China. Rabbit anti-Bcl-2, Bax, NF-кB p65,

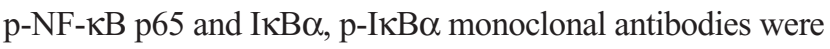
from Cell Signaling Technology, Beverly, MA, USA. Rabbit anti-HO-1 polyclonal antibody were from Abcam Corporation, Cambridge, MA, USA. TRIzol assay kit and one step reverse transcription polymerase chain reaction (RT-PCR) kit were from Thermo Fisher Scientific, Waltham, MA, USA. Caspase 3, Caspase 8, Caspase 9 activity detection kit were from Nanjing KeyGen Biotechnology Corporation Limited, Nanjing, People's Republic of China. TNF- $\alpha$, IL-1 $\beta$, IL-6 and IL-8 ELISA assay kit were from R\&D System, Minneapolis, MN, USA. TUNEL assay kit were from Wuhan Boster Biotechnology Corporation Limited, Wuhan, People's Republic of China. Electrophoresis, electrophoresis transfer and gel imaging system were from BioRad Laboratories, Hercules, CA, USA. Microplate reader were from TECAN Trading AG, Männedorf, Switzerland.

\section{Grouping and drug administration}

Thirty-six rats were randomly divided into sham operation, ICH model and ZPP group, with 12 rats in each group. The latter two groups were replicate models of ICH. At 30 minutes postoperative, rats in the ZPP group were injected with $10 \mathrm{mg} / \mathrm{kg}$ ZPP intraperitoneally, while the other two groups were given the same amount of normal saline. ${ }^{10}$

\section{Establishment of ICH model}

After being anesthetized with $10 \%$ chloral hydrate, rats were placed on operating table in a supine position, and $50 \mu \mathrm{L}$ of autologous blood was extracted from the femoral artery via a microsyringe. At the incisor, $2.3 \mathrm{~mm}$ below the ear tip, $0.2 \mathrm{~mm}$ from the bregma and $3.0 \mathrm{~mm}$ to the right of the midline, a hole with a diameter of $1.00 \mathrm{~mm}$ was made; $50 \mu \mathrm{L}$ of the autologous blood was injected perpendicularly to the caudate nucleus of the rats via a microsyringe, at a rate of $20 \mu \mathrm{L} / \mathrm{min}$. Needle remained inserted for 10 minutes after injection.

For the sham operation group, $50 \mu \mathrm{L}$ of physiological saline was injected instead, while the rest of the steps were similar to the ICH model..$^{10,13,14}$

\section{Neurological behavioral score}

At postoperative day 3, neurological function of the rats in each group was evaluated with Zea Longa 5-point scoring system: 0 point, no symptom of nerve injury; 1 point, forepaw unable to be fully extended; 2 points, paralysis of limb on one side, emergence of rear-end phenomena; 3 points, tend to collapse upon walking, unable to stand; 4 point, unable to walk spontaneously, loss of consciousness. ${ }^{13,14}$ 


\section{Detection of the brain water content}

Rats were sacrificed at postoperative day 3 . Brain tissue from the cerebral hemorrhage area was taken and residual blood of the specimen was cleaned with physiological saline. Excess water was dried with towel. Specimen was weighed with electronic balance, placed in $100^{\circ} \mathrm{C}$ oven for 24 hours and reweighed. Brain water content was calculated according to the wet and dry weight method.

Brain water content $=\frac{\text { Wet weight }- \text { Dry weight }}{\text { Wet weight }} \times 100 \%{ }^{15}$

\section{Detection of brain tissue HO-I mRNA expression with RT-PCR}

Total RNA was extracted from tissues using TRIzol reagent (Beijing ComWin Biotechnology Corporation Limited, Beijing, People's Republic of China). Purity of RNA was evaluated with microspectrophotometer (Thermo Fisher Scientific). RNA was subjected to one step reverse transcription. Quantitative PCR was performed. The reverse transcription system was: total RNA template $2 \mu \mathrm{L}(1 \mu \mathrm{g})$, dNTP mixture $2 \mu \mathrm{L}$, $\mathrm{MgCl}_{2} 2 \mu \mathrm{L}, 1$-ethyl-3,3'-dimethylamino-propyl- carbodiimide (EDPC) and added with distilled water up to $25 \mu \mathrm{L}$. Reaction parameter was: $95^{\circ} \mathrm{C}$ denaturation for 4 minutes, $95^{\circ} \mathrm{C}$ denaturation for 40 seconds, $58^{\circ} \mathrm{C}$ annealing for 30 seconds, $72^{\circ} \mathrm{C}$ extension for 30 seconds, for 40 cycles. HO-1 upstream primer sequences: $5^{\prime}$-CTATCGTGCTCGCATGAAC-3', downstream primer sequences: 5'-CAGCTCCTCAAACAGCTCAA-3', length $118 \mathrm{bp}$; GAPDH upstream primer sequences: 5'-ACTCCCATTCCTCCACCTTT-3', downstream primer sequences: 5'-TTACTCCTTGGAGGCCATGT-3', length $143 \mathrm{bp}$.

\section{Detection of brain tissue HO-I positive expression with immunohistochemistry}

Brain tissue specimen from the cerebral hemorrhage area was fixed in $10 \%$ formaldehyde solution for 24 hours, washed with running water, and paraffin-embedded. This was followed by 3-5 $\mu \mathrm{m}$ serial slicing, xylene dewaxing, and $70 \%, 75 \%, 80 \%$, $85 \%$ and $95 \%$ gradient alcohol dehydration. Specimen was then incubated with $3 \%$ hydrogen peroxide for 10 minutes and washed with phosphate buffered saline (PBS). This was followed by antigen retrieval, washed with PBS and blocked with goat antiserum for 1 hour. Specimen was incubated with primary antibodies (dilution 1:200) at $4^{\circ} \mathrm{C}$ overnight and washed with PBS, then with secondary antibodies (dilution 1:500) at room temperature and washed with PBS. This was followed by 3,3'-Diaminobenzidine (DAB) staining (Nanjing KeyGen Biotechnology Corporation Limited) for 20 seconds, rinsed with tap water, and restained for 1 minute, dehydrated, cleared and then mounted. PBS was used as negative control for primary antibodies. Cell cytoplasm or membrane which stained brown or yellowish dark brown under inverted microscope (Olympus Corporation, Shinjuku-ku, Tokyo, Japan) was counted as positive. Average optical density was measured with Image J software (National Institutes of Health, Bethesda, MD, USA) for positive cell rate.

\section{Detection of hippocampus apoptosis with TUNEL method}

Brain tissue specimen from the cerebral hemorrhage area was immersed in $10 \%$ neutral formalin for 24 hours, paraffinembedded, sliced and washed with PBS. This was followed by cell permeability with cell permeable liquid Triton $\mathrm{X}$ (Shanghai Solarbio Bioscience \& Technology Corporation Limited, Shanghai, People's Republic of China) and washed with PBS. TUNEL reaction solution was added and incubation was done in dark for 60 minutes at room temperature. Then, specimen was washed with PBS and stained with DAB (Nanjing KeyGen Biotechnology Corporation Limited) for 30 seconds, mounted and examined under microscope. Apoptosis was observed under light microscopy (200 fold). Apoptotic cells appeared yellowish brown.

Apoptosis index $(\mathrm{AI})=\frac{\text { Number of apoptotic cells }}{\text { Total cells }} \times 100 \%$.

\section{Detection of Caspase 3, Caspase 8 and Caspase 9 activity with colorimetric method}

A portion of brain tissue from the cerebral hemorrhage area was homogenized. Caspase 3, Caspase 8 and Caspase 9 activity were detected according to the kit instructions.

\section{Determination of TNF- $\alpha$, IL- I $\beta$, IL-6 and IL-8 level with ELISA}

A portion of brain tissue from the cerebral hemorrhage area was homogenized. The levels of TNF- $\alpha$, IL-1 $\beta$, IL-6 and IL- 8 were measured according to the kit instructions.

\section{Detection of brain tissue NF- $\kappa B$ signaling pathway related protein expression with Western blot}

A portion of brain tissue from the cerebral hemorrhage area was homogenized. Radioimmunoprecipitation assay (RIPA; Beijing ComWin Biotechnology Corporation Limited), a strong lysis buffer was added. Cells were lysed and centrifuged at 10,000 rpm for 10 minutes. Protein was harvested 
and protein concentration was detected with BCA assay kit. This was followed by protein denaturation, sample loading, sodium dodecyl sulfate gel electrophoresis and wet membrane transfer. Specimen was incubated with primary

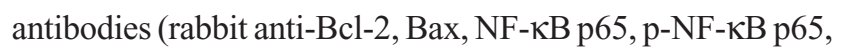
$\mathrm{I} \kappa \mathrm{B} \alpha$ and $\mathrm{p}-\mathrm{I} \kappa \mathrm{B} \alpha$ monoclonal antibodies, dilution $1: 100)$ at $4{ }^{\circ} \mathrm{C}$ overnight, and secondary antibodies (horseradish peroxidase labeled goat anti-rabbit $\operatorname{IgG}(\mathrm{H}+\mathrm{L})$, dilution $1: 200)$ at room temperature for $1-2$ hours. This was followed by exposure in gel imaging system. Quantity One software (Bio-Rad Corporation) was used to analyze the gray scale value of each antibody strip.

\section{Data analysis}

All data were analyzed with SPSS 21.0 statistical software package (IBM, Armonk, NY, USA). Results were presented as mean and standard deviations $(\bar{x} \pm s)$. Significant difference between two groups were determined with Student's $t$-test. $P<0.05$ was taken as statistically significant.

\section{Results}

\section{Effect of ZPP on neurological deficit score in $\mathrm{ICH}$ rats}

Compared with the sham operation group, neurological deficit score in the ICH group was significantly increased $(P<0.01)$; while compared with ICH group, neurological deficit score in the ZPP group was significantly decreased $(P<0.01)$ (Table 1$)$.

\section{Effect of ZPP on brain edema in ICH rats}

Compared with the sham operation group, brain water content in the ICH group was significantly increased $(P<0.01)$; while compared with the ICH group, brain water content in the ZPP group was significantly decreased $(P<0.01)$ (Table 1$)$.

\section{Effect of ZPP on brain tissue HO-I expression in $\mathrm{ICH}$ rats}

Compared with the sham operation group, HO-1 positive expression in the ICH group was significantly increased

Table I Effect of ZPP on neurological deficit score and brain edema in $\mathrm{ICH}$ rats $(\bar{x} \pm s)$

\begin{tabular}{lll}
\hline Group & $\begin{array}{l}\text { Neurological } \\
\text { behavior score }\end{array}$ & $\begin{array}{l}\text { Brain water } \\
\text { content (\%) }\end{array}$ \\
\hline Sham operation & $0.00 \pm 0.00$ & $75.19 \pm 7.08$ \\
ICH & $2.68 \pm 0.26 * *$ & $79.65 \pm 6.48^{* * *}$ \\
ZPP & $1.43 \pm 0.14^{\# \#}$ & $76.32 \pm 7.63^{\#}$ \\
\hline
\end{tabular}

Notes: $* * P<0.01$ compared with sham operation group; ${ }^{\# P<0.01}$ compared with $\mathrm{ICH}$ group. Number of rats, $\mathrm{n}=\mathrm{I} 2$ in each group. Data presented as mean \pm standard deviation.

Abbreviations: ICH, intracerebral hemorrhage; ZPP, zinc protoporphyrin.
$(P<0.01)$; while compared with the ICH group, HO-1 positive expression in the ZPP group was significantly decreased $(P<0.01)$ (Figure 1A and C).

Compared with the sham operation group, HO-1 mRNA expression in the ICH group was significantly increased $(P<0.01)$; while compared with the ICH group, HO-1 mRNA expression in the ZPP group was significantly decreased $(P<0.01)$ (Figure 1B and C).

\section{Effect of ZPP on brain cell tissue apoptosis in $\mathrm{ICH}$ rats}

Compared with the sham operation group, brain cell tissue apoptosis rate in the ICH group was significantly increased, $(P<0.01)$; while compared with the ICH group, brain cell tissue apoptosis rate in the ZPP group was significantly decreased $(P<0.01)$ (Figure $2 \mathrm{~A}$ and $\mathrm{B})$.

\section{Effect of ZPP on brain tissue Caspase 3, Caspase 8 and Caspase 9 activity in $\mathrm{ICH}$ rats}

Compared with the sham operation group, brain tissue Caspase 3, Caspase 8 and Caspase 9 activity in $\mathrm{ICH}$ group was significantly increased $(P<0.01)$; while compared with the ICH group, brain tissue Caspase 3 , Caspase 8 and Caspase 9 activity in the ZPP group was significantly decreased $(P<0.01)$ (Table 2$)$.

\section{Effect of ZPP on brain tissue inflammatory factors in $\mathrm{ICH}$ rats}

Compared with the sham operation group, the level of TNF- $\alpha$, IL-1 $\beta$, IL-6 and IL- 8 in the ICH group was significantly increased $(P<0.01)$; while compared with the ICH group, the level of TNF- $\alpha$, IL-1 $\beta$, IL-6 and IL- 8 in the ZPP group was significantly decreased $(P<0.01)$ (Table 3$)$.

\section{Effect of ZPP on brain tissue Bax and $\mathrm{Bcl}-2$ protein expression in $\mathrm{ICH}$ rats}

Compared with the sham operation group, Bax expression was upregulated and Bcl-2 expression was downregulated in the ICH group $(P<0.01)$; while compared with the ICH group, Bax expression was downregulated and Bcl-2 expression was upregulated in the ZPP group $(P<0.01)$ (Figure 3A and B).

\section{Effect of ZPP on brain tissue NF- $\kappa B$ signaling pathway in $\mathrm{ICH}$ rats}

Compared with the sham operation group, the level of phosphorylated NF- $\kappa \mathrm{B}$ p65 and $\mathrm{I} \kappa \mathrm{B} \alpha$ in the $\mathrm{ICH}$ group 
A

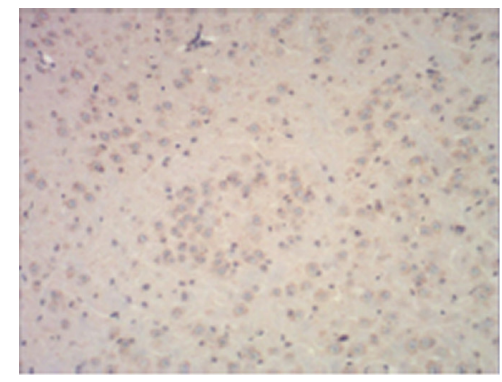

Sham operation group

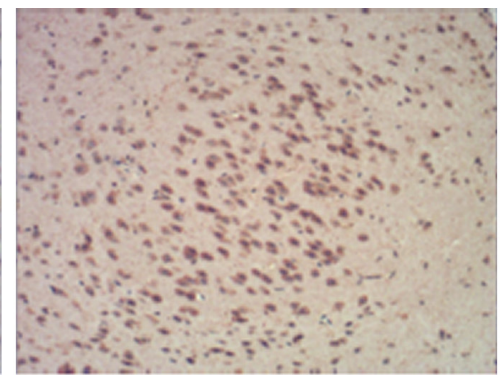

$\mathrm{ICH}$ group

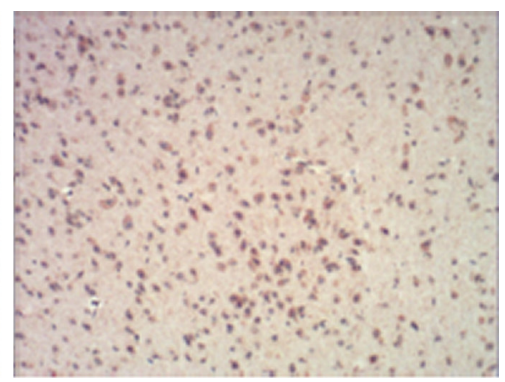

ZPP group

B
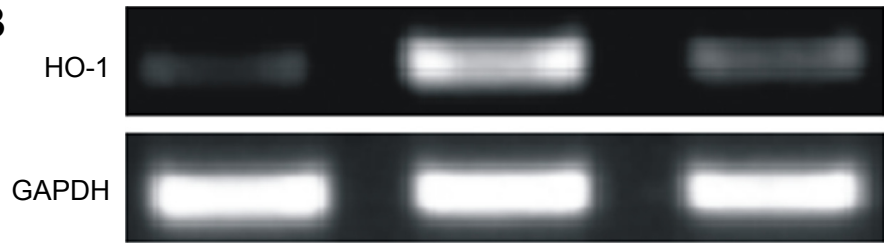

Sham operation group

C

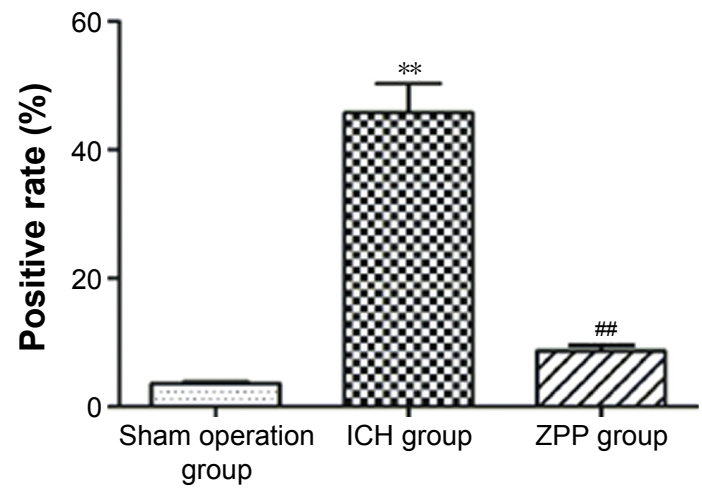

$\mathrm{ICH}$ group

ZPP group

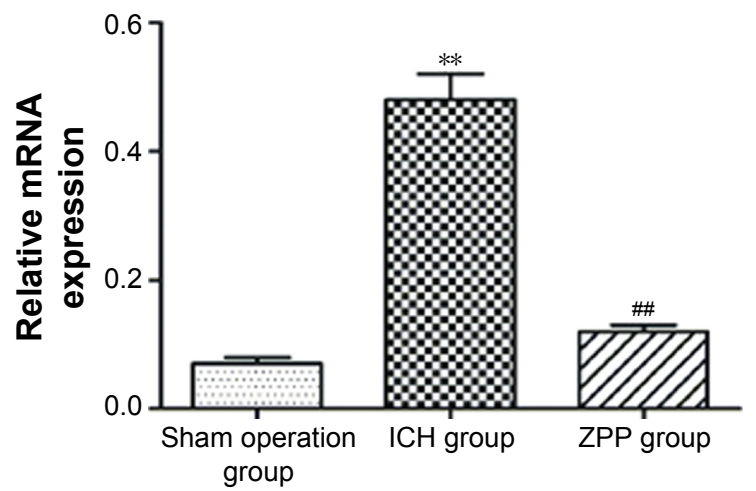

Figure I Effect of ZPP on brain tissue HO-I expression in ICH rats. (A) HO-I expression in rats detected with immunohistochemistry (magnification $\times 200)$. Number of rats, $\mathrm{n}=12$ in each group. (B) HO-I mRNA expression in rats detected with RT-PCR number of rats, $\mathrm{n}=12$ in each group. (C) Histogram of positive expression rate and relative $\mathrm{HO}-\mathrm{I}$ mRNA expression in rats. ${ }^{* * P}<0.0 \mathrm{I}$ compared with sham operation group, ${ }^{\#} \mathrm{P}<0.0 \mathrm{I}$ compared with ICH group. Number of rats, $\mathrm{n}=2$ in each group. Abbreviations: GADPH, glyceraldehyde 3-phosphate dehydrogenase; HO-I, heme oxygenase-I; ICH, intracerebral hemorrhage; RT-PCR, reverse transcription polymerase chain reaction; ZPP, zinc protoporphyrin.

was significantly increased $(P<0.01)$; while compared with the ICH group, the level of phosphorylated NF- $\kappa \mathrm{B}$ p 65 and $\mathrm{I} \kappa \mathrm{B} \alpha$ in the ZPP group was significantly decreased $(P<0.01)$ (Figure 4A and B).

\section{Discussion}

Cerebral edema and neuronal cell apoptosis could occur 3 hours after ICH. Cerebral edema that occurs at 24 hours is mainly related to thrombin products. Delayed cerebral edema that occurs after day 3 is mainly related to heme degradation products and this stage is the most critical time for long-term recovery of the neurological function after ICH. Thus, study of the key factors that affect the degradation of heme at this stage would have significant benefit for the recovery of neurological function and relief of cerebral edema. ${ }^{8,9}$
Studies have shown that HO is the most important enzyme that affects the catabolism of heme, and among these HO-1 is the most critical. $\mathrm{HO}$ catalyzes heme into biliverdin, $\mathrm{Fe}^{2+}$ and carbon monoxide, while biliverdin reductase reduces biliverdin to bilirubin. HO-1 is an inducible enzyme, found in animal liver microsomes by Tenhunen et al in $1968 .^{16}$ There are about 233 amino acids in human HO-1. Gene HO-1 is located in human chromosome $22 \mathrm{q} 12$. It consists of introns, exons and operon. Operon consists of heat shock element, AP-1, NF- $\mathrm{\kappa B}$ binding region and metal response element. HO-1 can be expressed in heart, brain, lung, intestine, liver, kidney and other tissues. ${ }^{11,12}$ Under normal physiological conditions, expression of HO-1 in brain tissue is very low or none at all. It increases rapidly in $\mathrm{ICH}$ and other brain injuries. 


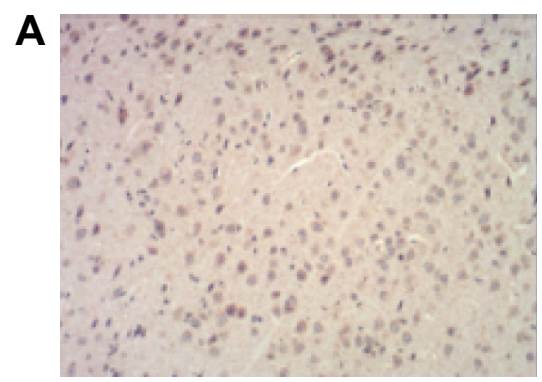

Sham operation group

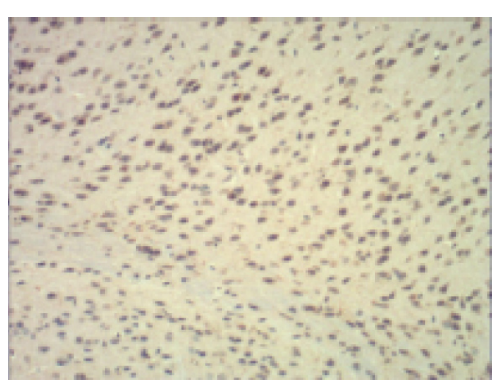

$\mathrm{ICH}$ group

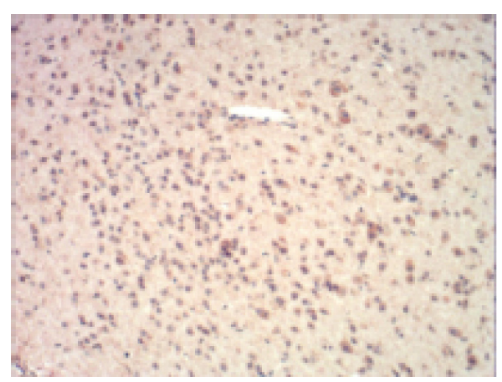

ZPP group

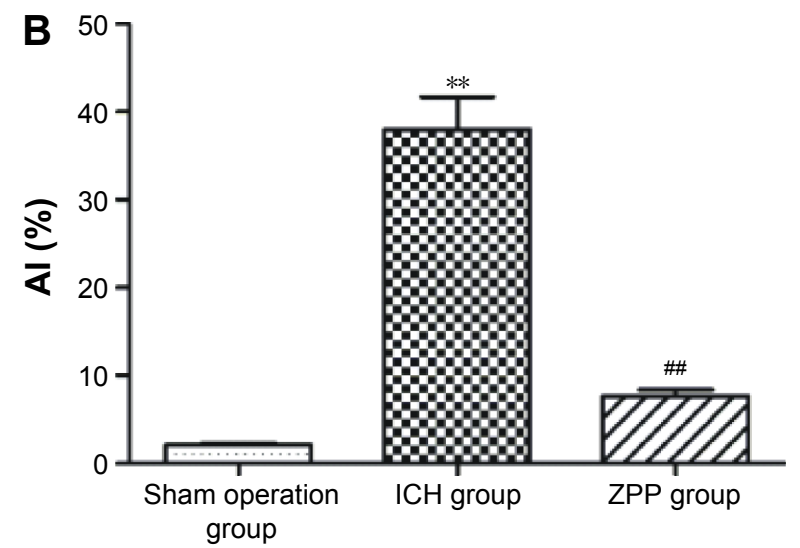

Figure 2 Effect of ZPP on brain cell tissue apoptosis in ICH rats. (A) Brain cell tissue apoptosis in rats (magnification $\times 200)$ number of rats, $n=12$ in each group. (B) Histogram of brain cell tissue $\mathrm{Al}$ in rats. $* * P<0.0 \mathrm{I}$ compared with sham operation group; ${ }^{\#} \mathrm{P}<0.0 \mathrm{I}$ compared with ICH group number of rats, $\mathrm{n}=\mathrm{I} 2 \mathrm{in}$ each group. Abbreviations: $\mathrm{Al}$, apoptosis index; $\mathrm{ICH}$, intracerebral hemorrhage; ZPP, zinc protoporphyrin.

In a study done by $\mathrm{Li}$ et $\mathrm{al}^{17}$ on the level of HO-1 in plasma and total bilirubin in 40 cases of ICH patients and 40 healthy controls, results showed that levels of HO-1 and total bilirubin were significantly higher in the ICH group compared to healthy controls. Multiple regression analysis showed that HO-1 and total bilirubin is closely related to ICH patients.

A study by Liu et al ${ }^{18}$ showed high level expression of IL-1, TNF- $\alpha$, HO- 1 and CD163 in ICH adult rats at 6-24 hours post ICH. The study also showed expression peaks at 72 hours, and at the same time pathological changes were significant and the apoptosis rate reached its peak. After 72 hours, the above changes weakened, but still higher than the normal group. Study by Wang et $\mathrm{al}^{19}$ showed that overexpression of HO-1 has damaging effects on ICH brain injury induced by ferrous citrate.

Table 2 Effect of ZPP on brain tissue Caspase 3, Caspase 8 and Caspase 9 activity in $\mathrm{ICH}$ rats $(\bar{x} \pm s)$

\begin{tabular}{llll}
\hline Group & $\begin{array}{l}\text { Caspase 3 } \\
\text { (U/mg) }\end{array}$ & $\begin{array}{l}\text { Caspase 8 } \\
\text { (U/mg) }\end{array}$ & $\begin{array}{l}\text { Caspase 9 } \\
\text { (U/mg) }\end{array}$ \\
\hline Sham operation & $0.87 \pm 0.09$ & $1.29 \pm 0.13$ & $3.21 \pm 0.32$ \\
ICH & $7.55 \pm 0.74^{* *}$ & $6.55 \pm 0.66^{* *}$ & $12.44 \pm 1.40^{* * *}$ \\
ZPP & $2.42 \pm 0.23^{\text {\# }}$ & $2.89 \pm 0.90^{\text {\#\# }}$ & $4.62 \pm 0.45^{\text {\#\# }}$ \\
\hline
\end{tabular}

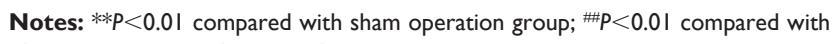
$\mathrm{ICH}$ group number of rats, $\mathrm{n}=12$ in each group. Data presented as mean \pm standard deviation.

Abbreviations: ICH, intracerebral hemorrhage; ZPP, zinc protoporphyrin.
Study by Zhang et $\mathrm{al}^{20}$ showed that high expression in early stage of ICH induced brain edema, inflammatory reaction, oxidative stress injury, increased MMP2 and MMP9 activity and accumulation of Fe ion in adult rats, while overexpression of HO-1 over a long period resulting from late stage of ICH led to absorption of hematoma, angiogenesis and recovery of part of the neurological function.

Study by Wang et $\mathrm{al}^{9}$ also showed increased expression in adult rats after ICH. HO-1 expression peaks at days 3 to 7 . At days 1 to 3, the amount of HO-1 expression was closely related to superoxide dismutase (SOD) activity, while at days 3 to $7 \mathrm{HO}-1$ expression was closely related with malondialdehyde (MDA) level, suggesting that $\mathrm{HO}-1$ has anti- as well as pro-oxidation effects in ICH. In the early stage of ICH, HO-1

Table 3 Effect of ZPP on the level of brain tissue inflammatory factors in $\mathrm{ICH}$ rats $(\bar{x} \pm s)$

\begin{tabular}{lllll}
\hline Group & $\begin{array}{l}\text { TNF- } \alpha \\
(\mathrm{pg} / \mathrm{mL})\end{array}$ & $\begin{array}{l}\text { IL-I } \beta \\
(\mathrm{pg} / \mathrm{mL})\end{array}$ & $\begin{array}{l}\mathrm{IL}-6 \\
(\mathrm{pg} / \mathrm{mL})\end{array}$ & $\begin{array}{l}\mathrm{IL-8} \\
(\mathrm{pg} / \mathrm{mL})\end{array}$ \\
\hline Sham operation & $4.17 \pm 0.42$ & $1.50 \pm 0.14$ & $1.43 \pm 0.13$ & $1.68 \pm 0.16$ \\
ICH & $32.45 \pm 3.2^{* *}$ & $30.73 \pm 3.03^{* *}$ & $24.55 \pm 2.46^{* *}$ & $15.43 \pm 1.54^{* *}$ \\
ZPP & $8.67 \pm 0.89^{\# \#}$ & $5.49 \pm 0.35^{\#}$ & $6.1 \pm 0.63^{\#}$ & $3.67 \pm 0.37^{\#}$ \\
\hline
\end{tabular}

Notes: $* * P<0.01$ compared with sham operation group; ${ }^{\# P<0.01}$ compared with ICH group. Number of rats, $n=12$ in each group. Data presented as mean \pm standard deviation.

Abbreviations: ICH, intracerebral hemorrhage; ZPP, zinc protoporphyrin. 

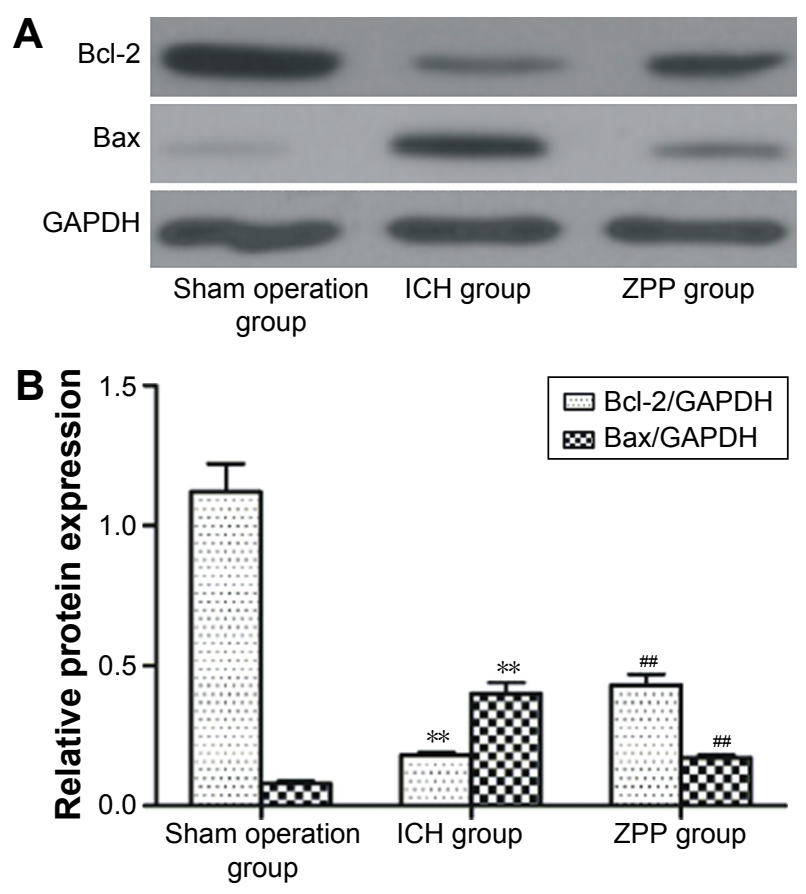

Figure 3 Effect of ZPP on brain tissue $\mathrm{Bax}$ and $\mathrm{Bcl}-2$ protein expression in $\mathrm{ICH}$ rats. (A) Brain tissue $\mathrm{Bax}$ and $\mathrm{Bcl}-2$ protein expression in rats. Number of rats, $\mathrm{n}=12$ in each group. (B) Histogram of brain tissue $\mathrm{Bax}$ and $\mathrm{Bcl}-2$ relative protein expression in rats. $* * P<0.01$ compared with sham operation group; ${ }^{\#} P<0.01$ compared with ICH group. Number of rats, $n=12$ in each group.

Abbreviations: GAPDH, glyceraldehyde 3-phosphate dehydrogenase; $\mathrm{ICH}$, intracerebral hemorrhage; ZPP, zinc protoporphyrin.

has a protective effect, while in the late stage, overexpression of HO-1 has injury effect. Thus, intervention with HO-1 as agent inducer or inhibitor in the treatment of ICH should be applied at different periods accordingly and day 3 post ICH is the cut-off point for HO-1 in order to take effect as an inducer or inhibitor. Therefore, in our study, brain tissue of the adult rats was examined at day 3 post ICH for its various activity changes, to evaluate the effect of HO- 1 in ICH.

Firstly, our study is designed according to the stereotactic technique reported. ${ }^{10,13,14}$ Fifty microliters of autologous blood from the femoral artery was injected into the caudate nucleus of the adult rats to establish an ICH model. At postoperative 30 minutes, ICH rats were treated with $10 \mathrm{mg} / \mathrm{kg}$ ZPP and at postoperative day 3 , rats were sacrificed and parameters were evaluated. Results showed that HO-1 positive rate and mRNA expression of rats in the ICH group were significantly increased, which is consistent with the study done by Wang et al, ${ }^{9} \mathrm{Li}$ et al ${ }^{17}$ and Liu et al, ${ }^{18}$ while ZPP significantly reduced brain tissue HO-1 expression in post ICH rats. Our study also showed that ZPP as HO-1 inhibitor could significantly reduce the neurological function deficit score and brain water content in ICH rats, suggesting that overexpression of HO-1 at day 3 post ICH has an inhibitory effect on the recovery of neurological function and relief of brain edema.
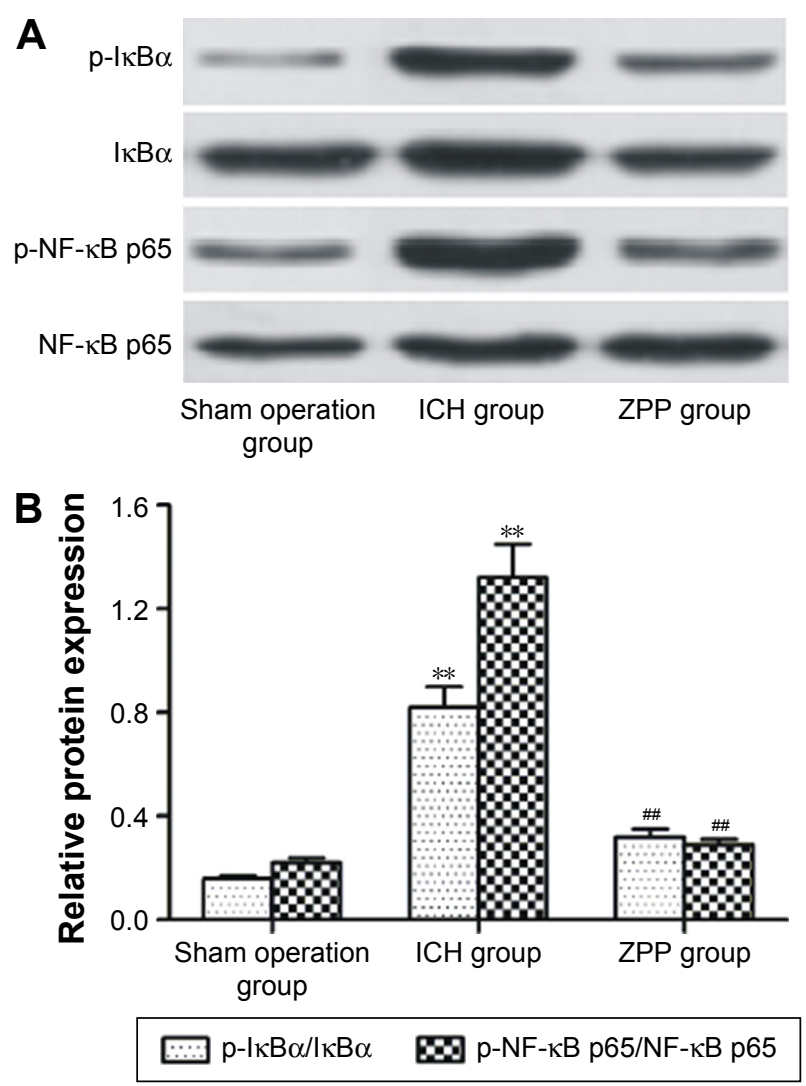

Figure 4 Effect of ZPP on brain tissue NF- $\kappa B$ signaling pathway in $\mathrm{ICH}$ rats. (A)

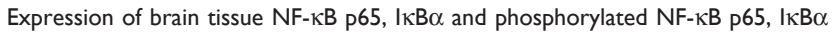
in rats. Number of rats, $n=12$ in each group. (B) Histogram of brain tissue NF$\kappa B$ p 65, I $\kappa B \alpha$ and phosphorylated NF- $\kappa B$ p 65, I $1 \kappa \alpha$ relative protein expression in rats. ${ }^{* * P} P 00$.0I compared with sham operation group; ${ }^{\#} P<0.0$ I compared with $\mathrm{ICH}$ group. Number of rats, $n=12$ in each group.

Abbreviations: $\mathrm{ICH}$, intracerebral hemorrhage; ZPP, zinc protoporphyrin.

Inflammatory reaction and cell apoptosis importance has increased in the ICH process, which leads to cerebral edema and secondary brain injury. ${ }^{21,22}$ Activation of neutrophils, macrophages and microglia enhances secretion large amount of inflammatory factors, such as TNF- $\alpha$, IL-1 $\beta$, IL- 6 and IL-8, etc. which further aggravates brain nerve and secondary brain tissue injury. ${ }^{23}$ Our study showed that the levels of TNF- $\alpha$, IL-1 $\beta$, IL- 6 and IL- 8 in the brain tissue were significantly increased after ICH, while HO-1 inhibitor, ZPP could significantly reduce the level of the above inflammatory factors, suggesting that inhibition of HO-1 expression, can to a certain extent, could inhibit post ICH inflammatory reactions and its links to neurological injury.

We further evaluated the effect of ZPP on ICH brain cell apoptosis with TUNEL method, and the results showed that ZPP could significantly reduce post ICH brain cell apoptosis. Brain cell apoptosis is an active and orderly natural process form of death, the occurrence of which might be related to the imbalance between the antiapoptotic and proapoptotic gene expression in the tissues. ${ }^{24,25}$ Among these, Bcl-2 family is 
currently the most widely studied apoptosis regulating gene family. Bcl-2 is the most common antiapoptosis gene, which can form heterodimer with Bax proapoptotic gene, or Bax itself can form dimer, and can regulate cell apoptosis. ${ }^{26}$ Under normal condition, Caspase is present as inactive zymogen in cells. When stimulated by the upstream apoptotic signal, the initiation factor of Caspase (Caspase 8 and Caspase 9) become activated after undergoing self-cleaving or being cleaved by other kinases, and transmit apoptotic signaling cascade which is eventually delivered to the Caspase family execution factor, Caspase 3 and induced cell apoptosis. ${ }^{27,28}$ Thus, in our study, Western blot and ELISA were used to detect Bax and Bcl-2 protein expression, Caspase 3, Caspase 8 and Caspase 9 activity in the brain tissue of each group of rats respectively. Results showed that ZPP could significantly upregulate Bcl-2 expression, downregulate Bax expression and reduce Caspase 3, Caspase 8 and Caspase 9 activity, suggesting that it inhibits the expression of HO-1, regulates the expression of apoptosis related protein and finally inhibits the apoptosis of brain tissue in post ICH rats.

Inflammatory reactions and cell apoptosis are regulated by various signaling pathway. Among these, NF- $\mathrm{BB}$ signaling pathway is the most frequently studied. ${ }^{29,30} \mathrm{NF}-\kappa \mathrm{B}$ belongs to the family of Rel protein, which comprises of two subunits, p50 and p65. In the resting state, NF- $\mathrm{BB}$ and $\mathrm{I} \kappa \mathrm{B} \alpha$ upstream signaling protein form complex in the cytoplasm. Under stimulation of the apoptotic signal or inflammatory factors, I $\mathrm{B}$ degrades after phosphorylation and separates

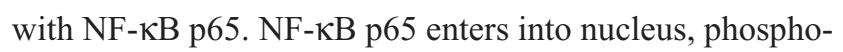
rylates at serine 536 site, further regulates the expression of its target proteins such as Bax, Bcl-2, Caspase 3, TNF- $\alpha$, IL- $1 \beta$ and IL- 6 , and mediates the apoptosis and inflammatory reaction. ${ }^{29,30}$

Meanwhile, a study by Yin et $\mathrm{al}^{10}$ showed overexpression of HO-1, and upregulation of NF- $\mathrm{KB}$ and TNF- $\alpha$ expression in $\mathrm{ICH}$ adult rats, could be inhibited after being treated with HO-1 inhibitor ZPP, suggesting that HO-1 might inhibit post $\mathrm{ICH}$ inflammatory reactions through the regulation of $\mathrm{NF}-\kappa \mathrm{B}$ and TNF- $\alpha$ expression.

Studies by Lee et $a l,{ }^{31}$ Seo et $\mathrm{al}^{32}$ showed that HO- 1 can mediate the inflammatory response of RAW 264.7 cells induced by lipopolysaccharide (LPS) via the regulation of

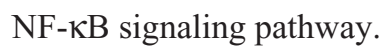

A study by Liu et $\mathrm{al}^{33}$ showed that LPS stimulates RAW264.7 macrophages to produce inflammatory reaction and release of inflammatory factors such as inducible nitric oxide synthase (iNOS) and nitric oxide (NO): These changes could be inhibited by administering HO-1 siRNA or PI3K inhibitor LY294002, and these are related to the inhibition of $\mathrm{NF}-\kappa \mathrm{B}$ activity. This suggested that the expression of HO-1 is closely related to the NF- $\kappa \mathrm{B}$ signaling pathway. Thus, in this study, we continue to explore the effect of HO-1 inhibitor ZPP on the level of phosphorylated NF- $\kappa$ B p65 and I $\kappa$ B $\alpha$ in the brain tissue of $\mathrm{ICH}$ rats, and our results showed that ZPP could significantly reduce the level of phosphorylated $\mathrm{NF}-\kappa \mathrm{B}$ p 65 and $\mathrm{I} \kappa \mathrm{B} \alpha$, suggesting that inhibition of HO-1 expression and further suppression of the NF- $\mathrm{KB}$ signaling pathway could significantly inhibit brain cell tissue apoptosis and inflammatory reaction in post ICH rats.

\section{Conclusion}

In summary, brain tissue HO-1 expression increased in day 3 post ICH rats. Administering of HO-1 inhibitor ZPP could significantly inhibit brain tissue apoptosis and inflammatory reaction in post $\mathrm{ICH}$ rats, and this is closely related to its inhibition of TNF- $\alpha$, IL-1 $\beta$, IL- 6 and IL- 8 inflammatory factors secretion and the regulation of cell apoptosis related protein expression, probably via the NF- $\kappa B$ signaling pathway.

\section{Acknowledgment}

This study is under the Key Projects of the National Science \& Technology Pillar Program during the Twelfth Five-year Plan Period (Project No: 2011BAI08B05).

\section{Disclosure}

The authors report no conflicts of interest in this work.

\section{References}

1. Ziai W, Nyquist P, Hanley DF. Surgical strategies for spontaneous intracerebral hemorrhage. Semin Neurol. 2016;36(3):261-268.

2. Askenase MH, Sansing LH. Stages of the inflammatory response in pathology and tissue repair after intracerebral hemorrhage. Semin Neurol. 2016;36(3):288-297.

3. Li P, Zhao SM, Hu YN, et al. [Advances in the pathogenesis of intracerebral hemorrhage]. Chin J Geriatr Heart Brain Vessel Dis. 2015;17(2): 214-215. Chinese.

4. Lin $\mathrm{H}$. [Research progress of Chinese and Western medicine treatment of cerebral hemorrhage]. China J Chin Med. 2013;28(7):1058-1059. Chinese.

5. Yaghi S, Eisenberger A, Willey JZ. Symptomatic intracerebral hemorrhage in acute ischemic stroke after thrombolysis with intravenous recombinant tissue plasminogen activator: a review of natural history and treatment. JAMA Neurol. 2014;71(9):1181-1185.

6. Zheng $\mathrm{H}$, Chen $\mathrm{C}$, Zhang J, et al. Mechanism and therapy of brain edema after intracerebral hemorrhage. Cerebrovasc Dis. 2016;42(3-4): 155-169.

7. Naidech AM. Diagnosis and management of spontaneous intracerebral hemorrhage. Continuum (Minneap Minn). Neurocritical Care. 2015;21(5): $1288-1298$.

8. Chen-Roetling J, Lu X, Regan RF. Targeting heme oxygenase after intracerebral hemorrhage. Ther Targets Neurol Dis. 2015;2(1):474. 
9. Wang G, Yang Q, Li G, et al. Time course of heme oxygenase-1 and oxidative stress after experimental intracerebral hemorrhage. Acta Neurochir (Wien). 2011;153(2):319-325.

10. Yin XP, Wu D, Zhou J, et al. Heme oxygenase 1 plays role of neuronprotection by regulating Nrf2-ARE signaling post intracerebral hemorrhage. Int J Clin Exp Pathol. 2015;8(9):10156-10163.

11. Liao YF, Zhu W, Li DP, et al. Heme oxygenase-1 and gut ischemia/ reperfusion injury: A short review. World J Gastroenterol. 2013;19(23): 3555-3561.

12. Zhang ZF, Liu SM, Xiu BH. [Research progression about role of hemeoxygenase-1 during brain injuries]. Prog Mod Biomed. 2011;11(5):961-963. Chinese.

13. Sun HL, Yu X. [Progress of studies on experimental animal models of intracerebral hemorrhage]. J Reg Anat Oper Surg. 2013;22(1):82-83. Chinese.

14. Lu HS, Yu CY, Tian Z Jia, et al. [Research progress of experimental animal model of intracerebral hemorrhage]. Chin J Neurosurg Dis Res. 2016;15(2):184-186. Chinese.

15. Shang HB, Hu YB, Yang DH, et al. [Edaravone attenuate secondary brain injury after intracerebral hemorrhage through activating Nrf2 pathway]. Chin J Neurosurg Dis Res. 2013;12(1):48-51. Chinese.

16. Tenhunen R, Marver HS, Schmid R. The enzymatic conversion of heme to bilirubin by microsomal heme oxygenase. Proc Natl Acad Sci USA. 1968;61:748-755.

17. Li X, Li C, Hou L, et al. Higher level of serum heme oxygenase-1 in patients with intracerebral hemorrhage. Int Surg. 2015;100(7-8): 1220-1224.

18. Liu B, Hu B, Shao S, et al. CD163/hemoglobin oxygenase-1 pathway regulates inflammation in hematoma surrounding tissues after intracerebral hemorrhage. J Stroke Cerebrovasc Dis. 2015;24(12): 2800-2809.

19. Wang LF, Yokoyama KK, Lin CL, et al. Knockout of ho-1 protects the striatum from ferrous iron-induced injury in a male-specific manner in mice. Sci Rep. 2016;6:26358.

20. Zhang Z, Song Y, Zhang Z, et al. Distinct role of heme oxygenase-1 in early- and late-stage intracerebral hemorrhage in 12-month-old mice. J Cereb Blood Flow Metab. Epub 2016 Jun 17.

21. Duan X, Wen Z, Shen H, et al. Intracerebral hemorrhage, oxidative stress, and antioxidant therapy. Oxid Med Cell Longev. 2016;2016:1203285.
22. Zhu Y, Liu C, Sun Z. Early combined therapy with pharmacologically induced hypothermia and Edaravone exerts neuroprotective effects in a rat model of intracerebral hemorrhage. Cell Biochem Biophys. 2015;73(2):581-587.

23. Chen S, Yang Q, Chen G, et al. An update on inflammation in the acute phase of intracerebral hemorrhage. Transl Stroke Res. 2015;6(1):4-8.

24. Esposito E, Cuzzocrea S. New therapeutic strategy for Parkinson's and Alzheimer's disease. Curr Med Chem. 2010;17(25):2764-2774.

25. Manucha W. Mitochondrial dysfunction associated with nitric oxide pathways in glutamate neurotoxicity. Clin Investig Arterioscler. 2016.

26. Antonsson B. Bax and other pro-apoptotic Bcl-2 family "killerproteins" and their victim the mitochondrion. Cell Tissue Res. 2001;306(3):347-361.

27. Kudelova J, Fleischmannova J, Adamova E, et al. Pharmacological caspase inhibitors: research towards therapeutic perspectives. J Physiol Pharmacol. 2015;66(4):473-482.

28. Yamaguchi Y, Miura M. Programmed cell death and caspase functions during neural development. Curr Top Dev Biol. 2015;114: 159-184.

29. Guo C, Liang F, Shah MW, et al. Hydrogen sulfide protected gastric epithelial cell from ischemia/reperfusion injury by Keap1 S-sulfhydration, MAPK dependent anti-apoptosis and NF-kappaB dependent antiinflammation pathway. Eur J Pharmacol. 2014;725:70-78.

30. Yin G, Wang Y, Cen XM, et al. Lipid peroxidation-mediated inflammation promotes cell apoptosis through activation of NF-kappaB pathway in rheumatoid arthritis synovial cells. Mediators Inflamm. 2015;2015:460310.

31. Lee J, Kang U, Seo EK, et al. Heme oxygenase-1-mediated antiinflammatory effects of Tussilagonone on macrophages and 12-Otetradecanoylphorbol-13-acetate-induced skin inflammation in mice. Int Immunopharmacol. 2016;34:155-164.

32. Seo YJ, Lee KT, Rho JR, et al. Phorbaketal A, Isolated from the marine sponge Phorbas sp., exerts its anti-inflammatory effects via NF-kappaB inhibition and heme oxygenase-1 activation in lipopolysaccharidestimulated macrophages. Mar Drugs. 2015;13(11):7005-7019.

33. Liu XH, Wang XL, Xin H, et al. Induction of heme oxygenase-1 by sodium 9-hydroxyltanshinone IIA sulfonate derivative contributes to inhibit LPS-mediated inflammatory response in macrophages. Cell Physiol Biochem. 2015;36(4):1316-1330.
Neuropsychiatric Disease and Treatment

\section{Publish your work in this journal}

Neuropsychiatric Disease and Treatment is an international, peerreviewed journal of clinical therapeutics and pharmacology focusing on concise rapid reporting of clinical or pre-clinical studies on a range of neuropsychiatric and neurological disorders. This journa is indexed on PubMed Central, the 'PsycINFO' database and CAS,

\section{Dovepress}

and is the official journal of The International Neuropsychiatric Association (INA). The manuscript management system is completely online and includes a very quick and fair peer-review system, which is all easy to use. Visit http://www.dovepress.com/testimonials.php to read real quotes from published authors. 